\title{
A Glimpse of the Aesthetic Characteristics of Chinese-style Piano Music Composition Through Tcherepnin
}

\author{
Rong Xing \\ Kunming University \\ Kunming, China
}

\begin{abstract}
By analyzing Chinese-style piano music composition under the background of a Russian musician Tcherepnin's teaching in the National Music School and holding of "Competition for Chinese-style Piano Works Composition" in 1930s, the thesis concluded that Chinese-style piano music is a crystallization of European and Asian piano music after combination. Thus, the author summarized that the poetic character of Chinese classical music culture, Chinese traditional music color harmony integration and rhythm (beat, meter) changes are the expression of the musical aesthetic features of form and content in Chinese-style piano music composition.
\end{abstract}

Keywords-Tcherepnin; Chinese-style piano music composition; poetic mood; color harmony integration; rhythm and meter

\section{INTRODUCTION}

Chinese piano music composition, as an independent music beauty, was like a sudden cultural phenomenon in the origin of Chinese music culture, and it has been mapped in China from the end of the Nineteenth Century to the early Twentieth Century. In history, the piano music culture was formed and developed in China for a hundred years. From Zhao Yuanren's first March of Peace in 1925 to the present, the fission of the piano music composition was absolutely impossible to generalize with the short language. But it is undeniable that at the start of Chinese piano music composition, composers tried to connect the European instruments to the national elements of China, so that the Chinese piano music has been telling the fundamental direction of the Chinese traditional music from the beginning of its birth. In 1930s, China was in the environment of internal turmoil, and the political changes in the great environment also produced the necessary and obvious help for China to begin to accept the advanced culture of Europe.

In the history of western music in the Twentieth Century, the romantic music style seemed to have come to the end. New music languages were constantly emerging. The music is no longer confined to presenting quiet country life and heart full of illusion, and not as the Impressionist music chasing the flickering moments. It used new material, new language, new technique, new thinking mode and even multiple modes of development. Many composers began to learn from oriental music and imitate the new language in their works. It seems that "exotic customs" can create new impetus for composition. Tcherepnin was one of the many followers. With the expansion of his activities, he has drawn the local music cultures everywhere in the world and became an important part of his composition. Tcherepnin's plan for the trip to the Far East of China and Japan was implemented. In 1934, he came to China of internal anxiety and external suffering, which made him seem to be aware of the mystery of Chinese classical music culture. Later he took three years traveling in China, which has deeply influenced and promoted the beginning of the composition of modern Chinese piano music.

The author thinks that most of Chinese piano music compositions in this thesis have specially combined the national melody and western composing techniques as $\mathrm{Mr}$. Tcherepnin emphasized in the course of teaching and holding competition, so that the original single melody is expanded to a multi-sound effect. China's national elements can get new vitality through this style of composition. It can be seen that from the composition and teaching thinking of Tcherepnin, he suggested and contributed to the idea of Chinese piano music composition from the artistic perspective of western culture and history. He made a new expression of exotic elements and Chinese national music elements in his works. Therefore, it can be felt that Mr. Tcherepnin wanted to get deep music aesthetic connotations with the combination of content and form through the integration of multi-national elements. This aesthetic trend also reveals the inheritance, promotion and development of Chinese national elements, and has an excellent driving effect.

\section{The Poetic Mood of ChInese Classical Music CULTURE}

In the history of China, there was a special group of literati music in traditional Chinese music. The cultural transmission of "elegance" from the earliest Book of Songs reveals imperceptibly the whole character of this group - "mood". This group pursued an aesthetic "artistic conception", which is light but not flighty, empty but not virtual. They were good at using dim, misty, vague tone and pitch to show quiet. With the sentiments of grieving over the passing of spring and feeling sad with the advent of autumn, they sprang into beautiful words from their heart. It may be specific poem and painting, or a lingering hesitation of a deep emotion. The feeling of 
integrating sense and mood, mind and nature, emotion and scenes is exactly the spirit of Chinese scholars who have been adhering to it.

It is such an obvious aesthetic difference that is applied to the composition of piano music, which gives Chinese and western views of aesthetic thinking with distinct personality differences. The East emphasizes on freehand writing and Zen, and falls on the slow track of emotion, while the West pays attention to realism, and focuses on how to express the stereoscopic description of objective things. It is the core and necessity for all piano music composers to reflect such traditional beauty spirit in Chinese piano works, embody "high" "far" "depth" and "empty" in the works, and integrate Chinese traditional classical aesthetic methods into works and compose vivid works with the combination of emotion and scenery.

Throughout Chinese piano works, the excellent works certainly have "mood" of objective concept. In fact, there are very few completely new works with the nature of certain artistic conception. Most of piano works are adapted from Chinese classical music or folk music. Generally, it can be divided into two types: one type contains works with the combination of emotion and reason, and the unity of form and spirit, such as Yangguan Farewell, Melody of White Feathers Garment and Three Plays of Plum Blossom. They all come from classic music. After adaptation and thickening of the texture, these works fully reflect the hearing and appreciation effect of melody first in Chinese traditional music. The other type contains works with the mutual infiltration and restriction of emotion and scenery, such as Flute and Drum at Sunset, Cowherd's Flute, Soliloquy at Cold Mountain Temple and Flowing Water. Some of these works originated from the artistic conceptions of traditional melodies, inheriting the aesthetic conception of the style and charm of Chinese traditional culture. It is precisely because of the influence of Chinese classical aesthetics, such as romantic charm, poetic mood and far empty that the overall composition of Chinese piano music has basically shown the features of implication, image out of image, environment beyond environment and achievement beyond rhyme.

\section{THE HARMONY INTEGRATION OF CHINESE TRADITIONAL MUSIC}

Chinese traditional music styles are very diverse. Especially the position and proportion of traditional music are absolutely second to none. Chinese traditional music is created by Chinese people in a long period of labor and social life. It is one of the most important forms of art which is the most direct reflection of reality and widely grasped and widely spread by the people. China is an ancient country centered on the Chinese land since ancient times and has 56 ethnic minorities. The various ethnic and regional differences in natural environment, customs and culture, intonation language and aesthetic habits have formed rich and diverse traditional music. It is indispensable for adaptation works of Chinese piano music to use melody of traditional music as material in the composition. Traditional music is the basic soil of people's life, so adapted piano works with traditional music melody as material is more favorable for the public. Piano music composition, which was formed by melody of national characteristics or regional characteristics, has kept the characteristics of the original folk music and new characteristics of piano music. The rewriting of melody is to expand and develop the original music through various creative techniques under the premise of keeping the large outline of original melody.

In general, there are the following situations: 1 . On the basis of preserving the original melody, apply variations and ornamented notes more or introduce contrastive ornamental materials, and almost don't break away from the structure of original song. The transcriptions that keep the original melody mostly use the title of original music, such as the piano adaptation work Selling Groceries (composed by a combination of two pieces of Guangdong ditties, Selling Groceries and Dresser. The structures of the two songs are short. The original melody of Selling Groceries is lively and humorous, and the melody of Dresser is mellow and coherent). The start of this work directly uses the original melody of Selling Groceries. The melody was almost the same, but only with slightly changes in speed and figure. It keeps the style and mood of the original music in "Fig. 1".

Score 1:

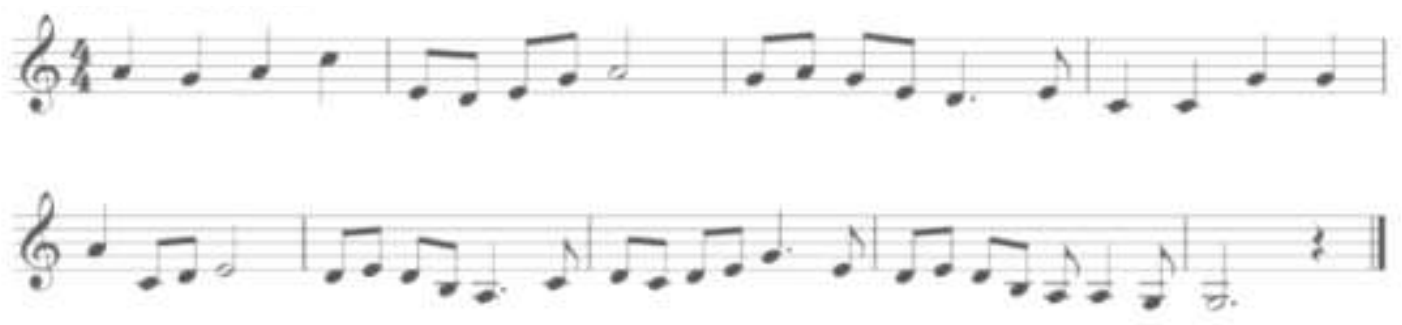

Fig. 1. Guangdong ditty: Selling Groceries.

Score 2: Piano transcription Selling Groceries: the melody first appears treble part. In basso it used staccato at later half beat, which makes the music lively and cheerful. It is a relatively typical accompaniment column-type chord. It is characteristic that the accompaniment form is always in the weak beat and does not make the collocation of the melody unevenly.

Wang Jianzhong's piano work Liuyang River also adopted the melody of traditional music. The melody came from a 
Hunan folk song Liuyang River. The piano work completely used the melody of original work in four sentences and repeated for three times. First is the melody of treble and add rhythmic accompaniment to basso. Second is the performing melody of basso and arpeggio decomposition accompaniment figure to treble to increase the feeling of turbulence. The third is the same as the first time with slight changes. While using the traditional music melody, the works also use different accompaniment figures to ornament the form of original melody and enhance rich music expression force in "Fig. 2", "Fig. 3" and "Fig. 4".

Score 3:
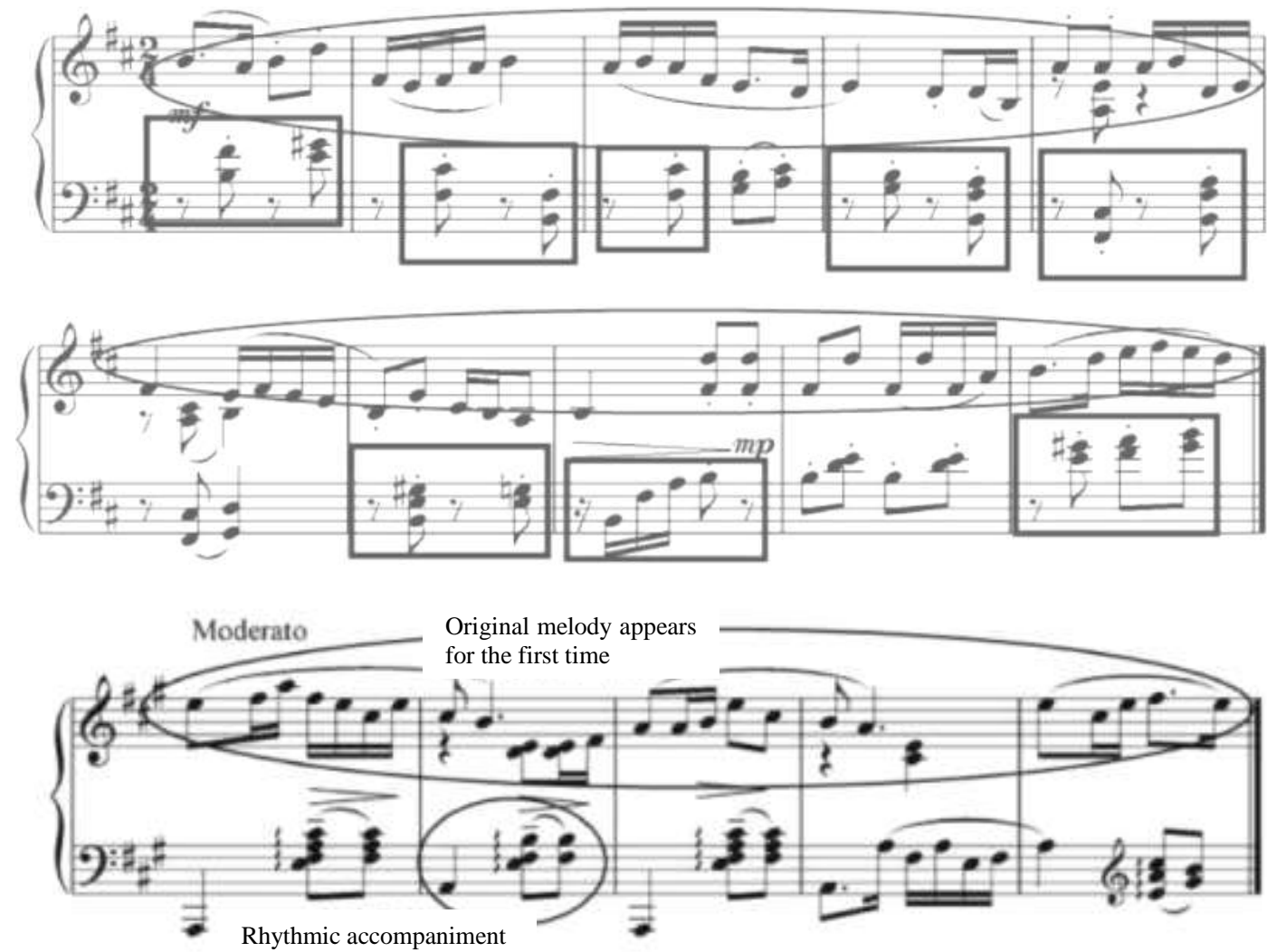

Fig. 2. Appears for the first time.

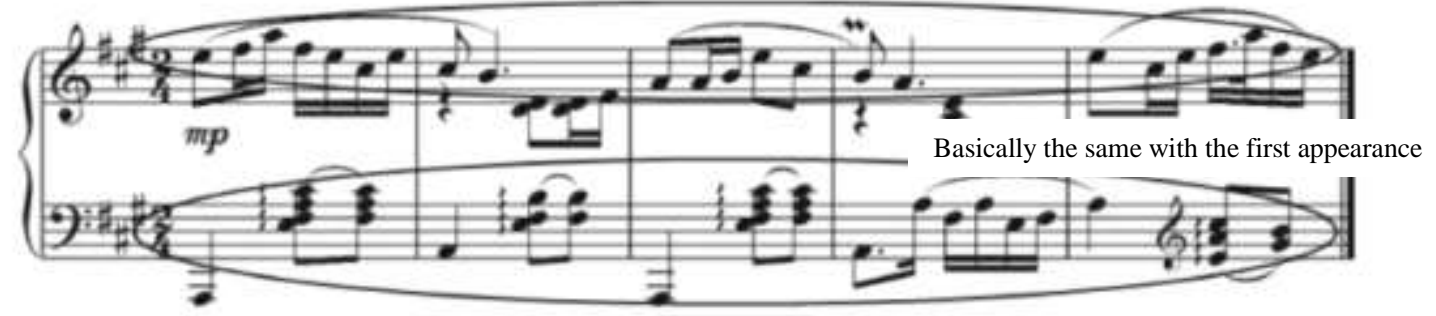

Fig. 3. Appears for the second time. 


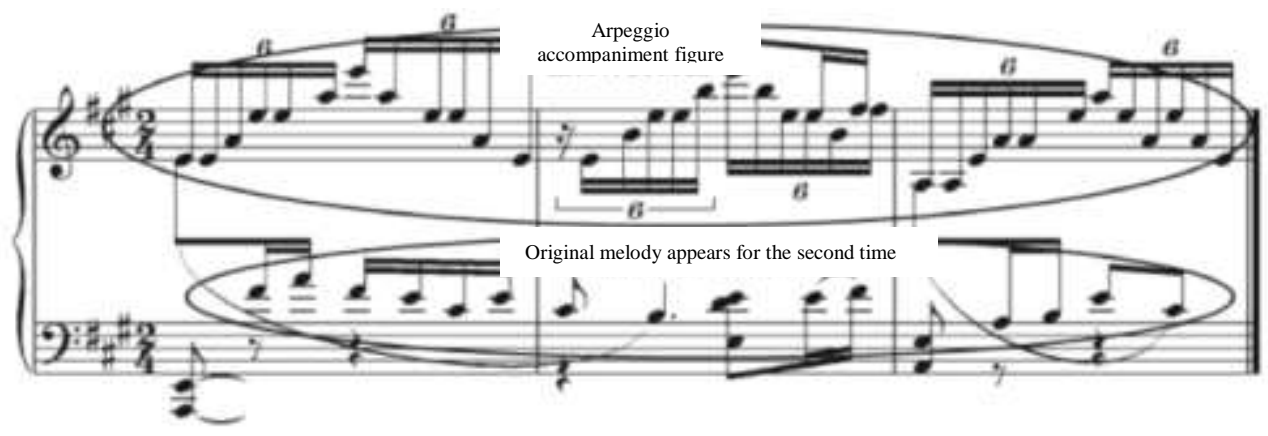

Fig. 4. Appears for the third time.

As the traditional music melodies are rooted in the production and living of the people, they are the real reflections of people's words and feelings, and the most genuine artistic reflection of people's thoughts and feelings. Therefore, it is surely the most direct and convenient way to use the original melody to compose and adapt piano works.

2. Extract and apply representative traditional music melodies to make greater adaptation, development and innovation. Happy Harvest Year was adapted from two northeast folk songs, and it kept their basic melodies. Although the work did not apply the melody of the original music directly, it retained the regional style and characteristics of the original melodies. Most of the melodies of northeast folk songs are mainly traditional hexatonic minors, and the melodies are very rich in local style. When composers transplant and adapt the traditional music tune, it is more than merely pure reappearance of the original tune, but to select the theme and content of original song and extract the representative material. Use the emotion vein of the original music as the main line of music development to reflect the new meaning of the music through the combination of different materials and different composition techniques.

3. Indirectly use or induce the characteristics or themes of traditional music and adopt the traditional music mode and composing techniques in the composition. The transcriptions, through the technique of comprehensive extraction of national mode and melody theme and material, not only inherited the national style of traditional music, but also fully displayed the characteristics of piano harmony style and wide range. On the one hand, it has embodied the common characteristic of traditional music melody, and maintained a strong national style. On the other hand, the development of music themes is more diverse.

The color of traditional music is more likely to be categorized as the expression of different folklore and different nationalities to different music. Therefore, the material of piano composition is rich and distinctive.

\section{THE TRANSFORMATION OF CHINESE TRADITIONAL RHYTHM (BEAT, METER)}

All ethnic groups have their own music. Different music has different rhythm and beat characteristics. Many representative music characteristics are expressed in rhythm. For example, the music of Gaoshan People in Taiwan is typical dance music. Therefore, the most prominent feature of Gaoshan music is its rhythmic dance music. "Someone used to compare music melody to flesh, comparing harmony to blood, and comparing rhythm to bone. When the body of life ends, the flesh decays and disappears gradually, and the fossils of the bones exist for a long time, which shows that rhythm plays an important role in music". Any music works cannot be separated from melody, harmony and rhythm, and they become the three key elements to determine the content of the works and the expression of the music image. Rhythm makes the content of the melody more vivid and makes the music image more lively and specific. The rhythm of Chinese traditional music is characterized by flexibility and diversity. The rhythm of western piano music is regular, and the composer has fixed the rhythm and beat before composition. Even if there is a change, it is only in a very small range. Chinese traditional music pays attention to the inner appeal. Different people, different environments and different moods express music of different speed, beat and rhythm. Traditional music is usually performed based on the personal understanding of the performer. Because of this, many traditional music uses elastic rhythms, so that there are many factors that allow performers to express their inner feelings freely and influence the rhythms of traditional music. One is the influence of local language. For example, traditional Xinjiang music usually uses syncopated notes, dots and upbeat. In the piano adaptation, the composer extracts the rhythmic type which has the ethnic characteristics and uses it in the music works to strengthen the ethnic style of the works. The original melody of adaptation work Kashgar Dance Music originates from the Uygur song and dance music Lapyer. The composer extracted the rhythm type of the Uygur song, and combined the extremely characteristic rhythm type with melody and mode, making the work with characteristics of Xingjiang music and culture in "Fig. 5", "Fig. 6" and "Fig. 7".

Score 4: 


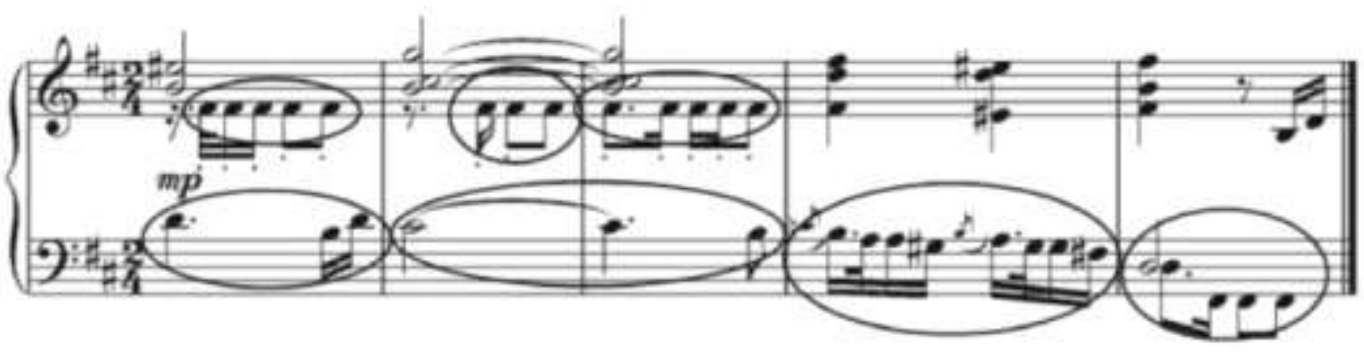

Fig. 5. Kashgar dance music.

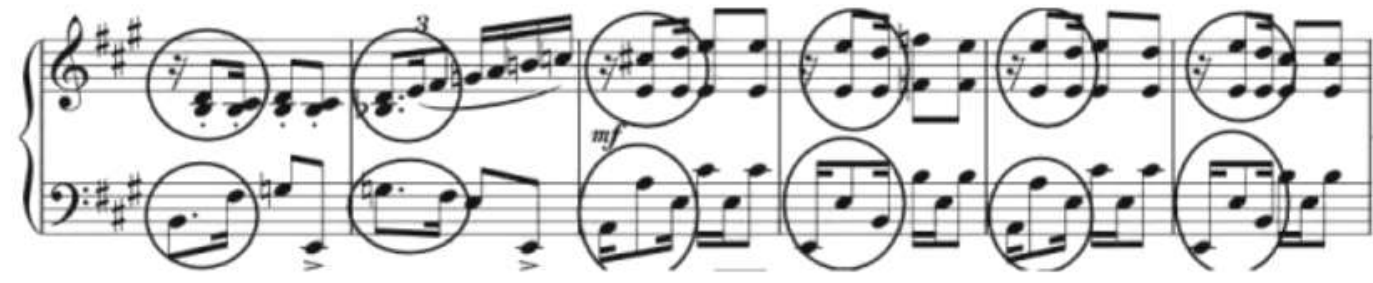

Fig. 6. Second Xinjiang dance music.

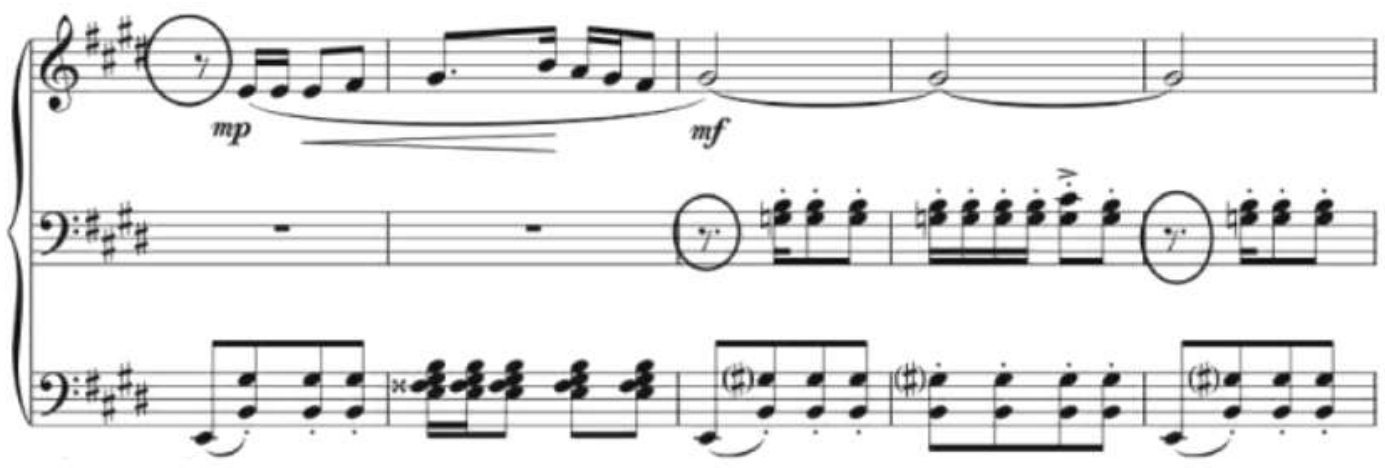

Fig. 7. Tajik Drum dance music.

The rhythm of traditional Chinese music often uses compound meter and ragtime. The stress position is not fixed. The strong and weak beat in music changes according to the expression needs of music content and emotion, and the strength of emotion determines the intensity of the rhythm. During the transplantation of traditional music, the composer retained this characteristic of traditional music. The intensity of the rhythm was closely related to the emotion of the music. Therefore, during the reappearance and transformation of adapted traditional piano works, it is not wise to process the rhythm of the music according to the "strong and weak" law of the rhythms in the western music. In the course of performance, arrange the strong and weak beats along with the development of music emotion, and the rhythm is not fixed. The use of compound meter and ragtime change the strong and weak rhythm rule of piano music and make music image more vivid and music development with liquidity. For example, the adapted work Tajik Drum Dance used a lot of compound meters which have syncopated stress and form complex beat between accompaniment figure and melody. Therefore, it is an alternated meter. In the Tajik music, the most common beats are quintuple meter and septuple meter. The stress of beat usually falls on the first and fourth beat, with an unstable feeling. This work has used the most commonly used compound meter of Tajik ethnic dance 5/8 meter. Its single beat is lively and jumpy, and the double beat is steady and powerful. The use of this compound beat made the music more dynamic and danceable and expression of ethnic character distinct.

There are a lot of traditional music in China, which are characterized by ragtime, such as mountain song, Mongolian long tune and Miao flying songs and Guqin song representing literati music. They are focused on ragtime or use a lot of ragtime. This kind of beat has no bar line and fixed weak and strong beats. Strong beats are according to the need of emotional development and the beat is determined by the inner feelings that the performer wants to express, perusing an aesthetic idea with dispersed form but undispersed spirit in Chinese traditional music. If we apply the strong and weak law of western music theory mechanically, it will produce an effect of neither fish nor flesh. Take the piano adaptation Sunset Drum as an example. The composer has used the structure of 
cause, course, transition and conclusion in the national instrumental music form, which used the techniques of variation, extension and circulation in Chinese traditional music. The work combines unequally-divided rhythm and equally-divided rhythm. Introduction uses free rhythm and this unequally-divided rhythm has both density and spacing. In the change there seems to be a power driving the development of music. It gives people an endless aftertaste space. In the performance, the music should be carried out and developed with inner feelings and leaded by the inner mind. As the introduction gradually enters and extends, and then gradually ends and disappears with the end. In the process of performance, the time value marked in the music score is only used as a reference for the overall outline of a sentence, but it cannot be played according to its number in "Fig. 8".

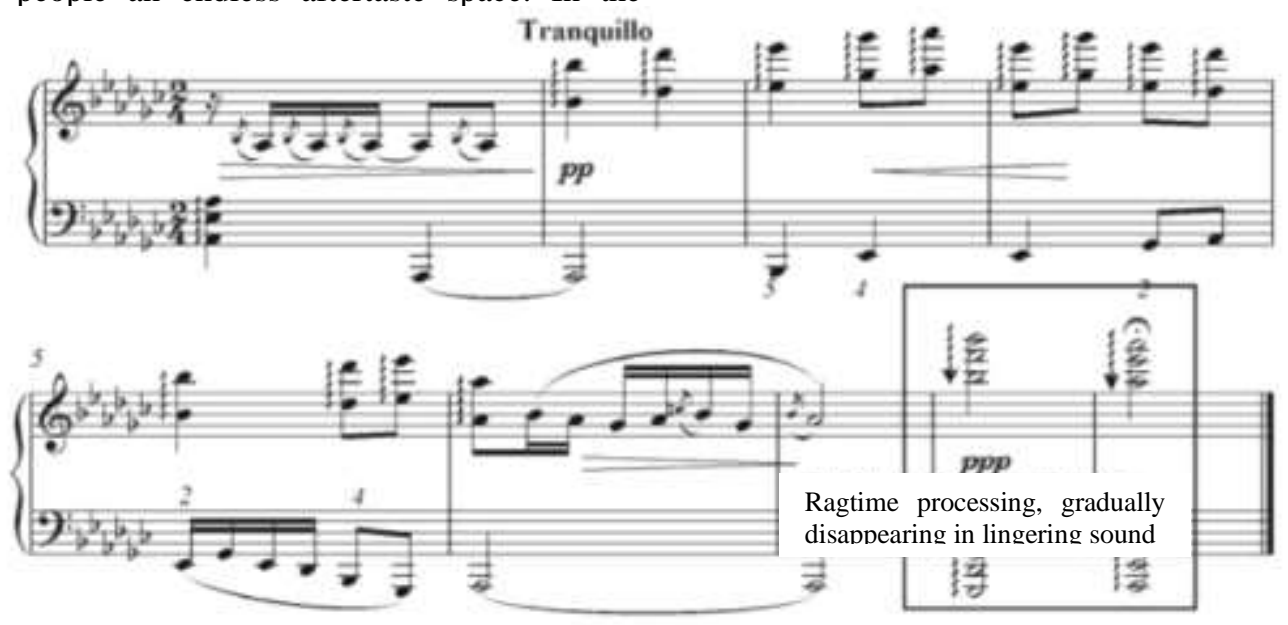

Fig. 8. Flute and Drum at Sunset.

\section{CONCLUSION}

The composition of Chinese piano music is a very special and long process. The combination of imported objects and our national works has lasted for half a century. After thousands of years, Chinese music and art culture once again had such a strong and harmonious voice by integrating with such exotic European instruments. The historical precipitation of Chinese musical culture has created rich aesthetic connotation, which has provided extremely rich aesthetic features for the composition of Chinese piano music after integration. Through the double enhancement of form and content, the piano music is full of national temperament and new aesthetic features of the times. It stands tall and upright. The aesthetic characteristics of Chinese music embodied in this process fully reflect the essence of spiritual culture in the long history of the nation. The historical mission of Chinese piano music is to preserve and pass down the essence and charm of our national music. It is also requirements for music color element of national character and skeletal rhythm. And it is the only source for Chinese piano music composition after Tcherepnin to gain unique and irreplaceable aesthetic value. With weak multi-vocal thinking, Chinese piano music has introduced all elements of Western composing theory into the polyphonicmode (heterophony) technique. This combination has formed a multi-vocal thinking and harmonic piano texture with national characteristics. In the process of composing national traditional music or folk songs into piano music without breaking the musical archetype, we imitate them and compose piano texture form from the interrelation of form and content to create an artistic conception of music and aesthetic temperament of national music and promote the development of national culture in the direction of philosophical aesthetics.
Chinese music culture itself is natural and simple, and it pursues a pure artistic beauty. The standard to judge a Chinese piano composition is to judge whether it can create this harmony, express deep feelings and thoughts with music and finally get the sublimation of emotion through the blending of scenes and emotions. So, when we look at the future of Chinese music, we shall always remember that the aesthetic concept and thinking of China passing down for thousands of years. Thus we can get the essences of our national music and preserve and continue its charm and glamour.

\section{REFERENCES}

[1] Zhao Xiaosheng. Chinese Piano Context. Piano Art, 2003 (4). 赵晓生. 中国钢琴语境 $[\mathrm{J}]$. 钢琴艺术.2003 (4).

[2] Wei Tingge. The Development of Piano Music Composition in China. Music Research, 1983 (2). 魏廷格.我国钢琴音乐创作的发展 [J]. 音 乐研究.1983 (2).

[3] Liao Shengjing. Writing of Chinese Pentatonic Mode Melody. Journal of Xinghai Conservatory of Music, 1998 (2). 廖胜京.中国五声调式旋 律的写作 [J]. 星海音乐学院学报.1998(2).

[4] Hao Sizhen. Multiplication and Development of Chinese-style Piano Works. Music Exploration, 2007 (6). 郝思震. 中国风格钢琴作品的多 元化繁衍与发展 $[J]$. 音乐探索. 2007(6).

[5] Wang Juanjuan. One Practice and Two Dignities - Value Differences of Piano Adaptation in the Western and Chinese Academia and Causes. People's Music, 2009 (7). 王娟娟.一种实践两种尊严一试论钢琴改编 曲在中、西方学界的价值差异及其原因 [J]. 人民音乐.2009 (7)

[6] Qian Rong. The Implicit Beauty Tendency of Chinese Traditional Music and Confucian Culture. Journal of Central Conservatory of Music 1997 (4). 钱茸. 中国传统音乐的含蓄美倾向与儒家文化 [J]. 中央音 乐学院学报. 1997 (4). 